\title{
STRATEGI KNOWLEDGE SHARING: UPAYA MENINGKATKAN KUALITAS SUMBER DAYA MANUSIA DI MADRASAH DINIYAH ANNAFI'IYAH PONDOK PESANTREN NURUL JADID
}

\author{
Imania \\ Universitas Nurul Jadid \\ Korespondensi: Jl. PP Nurul Jadid, Dusun Tj. Lor, Karanganyar, Kec. Paiton, \\ Probolinggo, Jawa Timur 67291 \\ e-mail: imai00905@gmail.com
}

\begin{abstract}
Asoek
Abstract: The purpose of this study is to apply knowledge sharing strategies to improve the quality of human resources in Nurul Jadid's Diniyah Annafi'iyah Madrasah. The research methodology used is a qualitative method with a case study approach. Data collection is done by interview and observation. the results of this research are knowledge sharing in improving the quality of human resources by means of, among others: 1) changing mental mindset and revolution 2) training 3) supervision 4) rewards and punishments. The results of knowledge sharing can add new knowledge or insights and experiences, so that the quality of human resources is maintained in the madrasa. The application of knowledge sharing strategies carried out by a leader can benefit the institution's own resources and can develop institutions to continue to advance better.
\end{abstract}

Keywords: Knowledge Sharing Strategy and Human Resources

\section{PENDAHULAN}

Pengetahuan sangat penting bagi setiap individu untuk melaksanakan aktifitas dalam kehidupan sehari-hari. Dengan pengetahuan, seseorang dapat mengetahui bagaimana cara mengerjakan tugasnya yang akan bermanfaat di kemudian hari untuk melakukan hal yang sama.(Cahyo Adi Suprapto dan Setiawan Assegaff, 2017: 532). Namun, sesuai dengan kondisi yang dihadapi oleh peserta didik, pendidik dan tenaga kependidikan (Sumber Daya Manusia) di Madrasah Diniyah Annafi'iyah di Pondok Pesantren Nurul Jadid, seperti kurangnya kemaksimalan jam belajar, kurangnya ketuntasan materi pembelajaran, kurangnya keaktifan siswa masuk kelas, keefektifitan siswa dalam belajar, kurangnya kedisiplinan siswa serta pendidik dan kurangnya perhatian pemimpin terhadap karyawan sendiri. Sehingga dengan keadaan sumber daya di madrasah tersebut sempat terfikirkan oleh para staf untuk mendapat pengetahuan yang lebih luas guna dapat merubah keadaan madrasah.

Madrasah merupakan tempat berlangsungnya proses pembelajaran dan proses pendidikan (Tim Redaksi, 2008: 435), oleh karena itu pendidikan merupakan peranan penting untuk membangun kualitas sumber daya manusia. Dengan adanya sumber daya manusia yang berkualitas maka kehidupan manusia akan berkembang lebih baik. Pendidikan merupakan usaha sadar yang dilakukan oleh seseorang untuk mewujudkan cita-citanya, sebab pendidikan yang berkualitas menjadi komponen besar bagi majunya suatu bangsa. (Bejo Agustinus Hari Hanggara dan Imanuel Sairo Awang, 2016: 80) Dikatakannya pendidikan yang bermutu ialah suatu hal yang diharapkan bagi bangsa, sehingga sumber daya manusia dapat diharapkan bisa melahirkan pendidikan yang berkompeten. Dan untuk meningkatkan 
kualitas pendidikan sangat di butuhkan adanya komitmen bersama antara seorang leader atau kepala madrasah, karyawan, pendidik, dan peserta didik sebagai stakeholder di suatu lembaga tersebut. Semakin tinggi komitmen bersama dalam berorganisasi maka semakin meningkatkan kinerja yang baik dan terpelihara keanggotaannya. Yaitu dengan cara memberi pelayanan yang baik, bekerja sungguh-sungguh serta berusaha mempertahankan diri untuk tetap bekerja di lembaga pendidikan.(Sudarsih Meria Fajar Aisyah dkk, 2017: 132)

Sumber daya manusia sangat diperlukan sebagai tenaga kerja pada suatu organisasi (M Nazar Almasri, 2016: 137). Kualitas sumber daya manusia mempengaruhi kinerja yang dihasilkan dan berdampak pada perusahaan. Sumber daya yang berkualitas perlu adanya kemampuan tanggung jawab pada setiap diri karyawan. Untuk mencapai kemampuan sumber daya yang bertanggung jawab bisa dicapai dengan bekal pendidikan, pelatihan dan pengalaman yang cukup, sehingga dapat melahirkan tenaga kerja yang baik dan berdampak baik bagi perusahaan. (Merisa Fajar Aisyah dkk, 2017) Salah satu terwujudnya kinerja yang baik dari karyawan ialah motivasi dari seorang pemimpin. Sehingga dapat membuat para karyawan bisa menunjukkan hasil kinerja yang maksimal dan memuaskan. Hal ini berkesinambungan dengan tujuan madrasah yang dapat dicapai dengan baik.(Jamaluddin A. dkk, 2016: 2)

Tercapainya tujuan madrasah diperlukan strategi pemimpin yang dapat mempengaruhi anggota yang dipimpinnya. Penanaman dan pembinaan keefektifitasan kepemimpinan dapat dilakukan dengan proses yang terrencana dengan baik, teratur dan terus berkelanjutan. (Jamaluddin A.Chairil dkk, 2016: 2) Pemimpin merupa- kan suatu penggerak jalannya organisasi, tanpa adanya seorang pemimpin tentu suatu lembaga tidak akan berjalan dengan baik dan maksimal, karena dinyatakan bahwa pemimpim adalah sebuah kunci utama dari seluruh kegiatan yang ada.(Jamaluddin A.Chairil dkk, 2016: 3)

Untuk mengatasi problematika yang ada di Madrasah Diniyah Annafi'iyah Nurul Jadid tersebut perlu adanya solusi untuk memecahkannya, yaitu diadakannya sharing terhadap kepala madrasah, sehingga kepala madrasah mempunyai kebijakan untuk dapat menerapkan knowledge sharing terhadap bawahannya melalui strategi pemimpin dalam meningkatkan kualitas SDM di madrasah. Untuk tetap mempertahankan sumber daya manusia yang ada di Madrasah Diniyah Annafi'iyah dikarenakan kebijakan dari seorang pemimpin yang bisa merubah mindset madrasah menjadi lebih baik seperti madrasah saat ini.

Salah satu langkah awal yang dapat dilakukan untuk meningkatkan kinerja karyawan di Marasah Diniyah Annafi"iyah Nurul Jadid ialah dengan dilakukannya knowledge sharing terhadap para karyawan, dengan tujuan agar para karyawan mendapat pengetahuan, informasi dan pengalaman yang baru (Viranda Vrizka dan Anita Silvianita, 2016: 1849). Karena dinyatakan bahwa "knowledge it self power" yaitu pergerakan dalam berbagi pengetahuan di abad ini merupakan sebuah kekuatan (Syifa Nur Rakhmah, 2017: 116).

Dari fenomena yang terjadi terdapat trasformasi kepemimpinan Madrasah Diniyah Annafi'iyah Nurul Jadid. Maka peneliti bertujuan untuk meneliti dan mengetahui: strategi yang dapat dilakukan untuk meningkatkan kualitas sumber daya 
manusia di Madrasah Diniyah Annafi'iyah Nurul Jadid melalui knowledge sharing?

\section{KA] LANTEOR}

\section{Konsep dasar Knowledge Sharing}

Istilah dari Knowledge Sharing berasal dari bahasa inggris yang mempunyai arti "Knowledge"(John M. Echols dan Hassan Shadily, 2010: 334) yang berarti pengetahuan atau ilmu, sedangkan "Sharing”( John M. Echols dan Hassan Shadily, 2010) ialah mempunyai arti berbagi, jadi arti dari pada Knowledge Sharing ialah berbagi pengetahuan. Secara terperinci Knowledge Sharing dapat diartikan interaksi antar individu yang bertujuan untuk meningkatkan dan mengembangkan diri setiap individu. (Nur Fauziyah Mayang Rumaisha dkk, 2014: 90) Daniel Ofori mendefinisikan bahwa "Knowledge sharing is a social action which takes palace through interaction and communication between individuals and giver benefit to another individual." Arti dari berbagi pengetahuan ialah terjadinya tindakan sosial melalui interaksi dan komunikasi antar individu dan bisa memberi manfaat bagi individu lainnya. (Daniel Ofori dkk, 2015: 158) Berdasarkan teori tersebut, dapat disimpulkan bahwa knowledge sharing ialah terjadinya interaksi antar individu atau individu dengan kolompok yang bertujuan untuk meningkatkan, menyalurkan dan mengembangkan pengetahuan terhadap diri individu.

Selain memberikan informasi atau pengetahuan terhadap orang lain, dalam melakukan knowledge sharing juga bisa mencapai dunia dan akhirat, hal ini sebagaimana dinyatakan dalam Hadits Nabi :

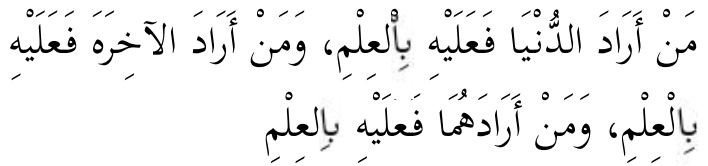

'Barang siapa yang menginginkan dunia maka raiblah dengan ilmu, barang siapa yang menghendaki akhirat maka raiblah dengan ilmu dan barang siapa yang menginginkan keduanya maka raiblah dengan ilmu." (H.R. Turmudzi)

Proses knowledge sharing berkaitan dengan pengalaman, keahlian individu dalam bekerja dan saling mempertukarkan pengetahuan secara bersama-sama.(Widodo, 2013: 19-20) Dengan menerapakannya knowledge sharing ini yang dapat meningkatkan inovasi karyawan untuk menghasilkan ideide baru ataupun metode baru sehingga dalam proses kerja akan semakin menambah pengetahuaan dan informasinya. Secara demikian, dengan mempertukarkan pengetahuan kepada setiap individu dapat memperbaiki efektivitas dan efisien pross karyawan. (Deny Bagus Aristanto 2017: 1541) Dan dengan melakukan knowledge sharing atau saling berbagi ilmu pengetahuan terhadap sesama individu maupun kelompok dengan harapan ialah untuk mencapai tujuan bersama. (Fajar Maulana dkk, 2018: 59)

Hoof dan Ridder memaparkan bahwasanya knowledge sharing ialah proses antar individu saling mempertukarkan pengetahuan melaluai tacik pengetahuan dan eksplisit pengetahuan (tacit knowledge dan explicit knowledge). (Ade Irma Susanty dkk, 2015: 25-26) Manajemen pengetahuan terbagi menjadi dua yaitu tacik pengetahuan dan eksplisit pengetahuan, yaitu pengetahuan tacit ialah pengetahuan yang diperoleh seseorang secara personal berdasarkan pengalamannya, sulit untuk diajarkan terhadap orang lain dan lebih banyak diketahui oleh orang tersebut dari pada yang disampaikan. (Desi Putri Wijayanti dan Didi Sundiman, 2017: 71) Pengetahuan tacit 
didapat secara personal atau tersembunyi maka dapat dicontohkan seperti halnya ingatan seseorang, hubungan pribadi, intuiri (gerak hati), pengalaman dan segala sesuatu yang di pelajari di setiap pekerjaannya. Mayang Rumaisha, Damayani, And Rohman. Pengetahuan eksplisit ialah pengetahuan yang dapat di sampaikan kepada orang lain sehingga mudah diterapkan dan dilukiskan ke dalam bentuk dokumen, pelatihan, praktek, teknologi dan lain-lainnya. (Desi Putri Wijayanti dan Didi Sundiman, 2017) Dikarenakan pengetahuan ekplicit merupakan pengetahuan yang didapat dalam bentuk dokumen atau pernyataan, sehingga pengetahuan ekplisit dapat disalurkan dengan mudah melalui komunikasi atau barbagai media. (Novian Setyaji Saputro dan Yuniadi Mayowan, 2018: 9).

\section{Strategi Kepemimpinan dalam Aktivitas Madrasah}

Istilah strategi berasal dari bahasa yunani yang mempunyai arti "strategos" yaitu tentara (memimpin). Dan secara terminologi strategi merupakan pengarahan besar yang bisa menggerakkan semua bawahan terhadap posisi yang menguntungkan sebelum pelaksanaan dimulai untuk meraih kemenangan. (Husaini Usman dan Nuryadin Eko Raharjo, 2013: 2)

Strategi pemimpin ialah kemampuan untuk berfikir secara strategis, tetap bertahan dalam kekeruhan dan mempunyai rencana untuk melakukan perubahan di masa depan dalam menciptakan suatu keunggulan yang kompetitif bagi lembaga. (Son Wandrial, 2011: 422) Dengan perubahan yang ada pada lingkungan, tentunya sebagai seorang pemimpin tidak merasa goyah dengan kondisi tersebut untuk mencapai tujuan yang telah ditetapkan sebelumnya. Oleh karena itu, seorang pemimpin dituntut untuk bisa menjadi pusat monitor dalam segala perubahan dan harus bisa berprilaku yang mendukung dengan tercapainya rencana tujuan lembaga. (Son Wandrial, 2011) Dengan adanya strategi yang dapat memberikan arah pengembangan dan pengelolaan sumber daya manusia terhadap lembaga pendidikan. Untuk mengembangkan sumber daya manusia merupakan rencana jangka panjang yang akan dilakukan oleh manusia sehingga kebutuhan para tenaga kerja dapat terpenuhi secara kuantitatif dan kualitatif. (Lijan Poltak Sinambela, 2017: 116)

Strategi merupakan kunci utama dalam meraih kesuksesan tujuan madrasah. Pemimpin yang baik ialah pemimpin yang mempuyai strategi bagus utuk memajukan lembaganya. Maka dari itu, tanpa adanya strategi maka seluruh program yang ada di madrasah tidak akan berjalan dengan baik. (Sakdiah Ibrahim Muhammad Hadi and Ibrahim Djailani, 2014: 42-43) Seorang kepala madrasah diharapkan bisa memecahkan masalah agar keputusan dapat diterapkan di masa depan dan dapat terimplementasi sesuai dengan rencana. Oleh sebab itu, seorang kepala madrasah perlu mengukur dan melihat telebih dahulu tentang lemahnya organisasi yang dimiliki, peluang untuk masa depan yang bisa dimafaatka dengan baik. (Sakdiah Ibrahim Muhammad Hadi and Ibrahim Djailani, 2014)

\section{Langkah-Langkah Knowledge Sharing untuk Meningkatkan Kualitas Sumber Daya Manusia}

Dari hasil penelitian menunjukkan bahwa di Madrasah Diniyah Annafi'iyah 
Nurul Jadid dalam menerapkan Knowledge Sharing yang dilakukan oleh sumber daya manusia di madrasah melalui strategi pemimpin, yaitu terdiri dari empat strategi yang bertujuan untuk meningkatkan kualitas sumber daya manusia yang ada di madrasah diniyah tersebut.

\section{Perubahan Mindset dan Revolusi Mental}

Strategi pertama yang dilakukan oleh kepala madrasah Diniyah Annafi'iyah Nurul Jadid melalui knowledge sharing ialah revolusi mental, yang mana revolusi mental merupakan langkah awal yang ditempuh untuk merubah mindset madrasah bahwa lembaga sama pentingnya dengan sekolah formal di pondok pesantren. Oleh sebab itu, munculnya sebuah mindset baru bahwa diniyah bukanlah pendidikan yang sekunder tapi madrasah diniyah juga sama pentingnya dengan lembaga formal, dikarenakan madrasah adalah sebagai tumpuan utama yang menyebabkan para santri tetap belajar di pesantren. Sehingga dengan perubahan pola pikir dan sistem baru dari seorang pemimpin dapat meningkatkan kualitas peserta didik, pendidik dan karyawan.

Sekolah madrasah menjadi peluang penting terpenuhinya tuntutan masyarakat yang memiliki kesadaran beragama dan berdakwah, dengan tujuan untuk menambah pengetahuan dalam bidang ilmu keagamaan dan ilmu umum. Dengan perubahan cara berfikir ini yang menganggap madrasa penting akan merubah pola fikir dan nilainilai madrasah itu sendiri. (Siswanto, 2014: 70-72) Dalam membangun revolusi mental atau membangun pendidikan tidak akan bisa efektif jika hanya melakukan perombakan lembaga saja tanpa harus melakukan perubahan budaya dan mempunyai fondasi yang kuat seperti halnya membangun karakter yang baik dari segi sumber daya manusia dalam lembaga pendidikan itu sendiri. (Buyung Syukron, 2016: 30) Karena itu, guru sebagai fondasi awal untuk melahirkan masyarakat terdidik, dengan membangun pola fikir positif peserta didik dan juga menjalankan proses pembelajaran dengan menambah pengetahuan peserta didik. (Muhammad Kristiawan, 2015: 21)

Untuk melakukan perubahan atau revolusi mental terhadap peningkatan kualitas SDM yang ada di madrasah. Maka madrasah sebagai tempat pendidikan agama perlu menyamaratakan sekolah formal dengan sekolah madrasah diniyah yang ada di pondok pesantren, yaitu dengan merubah sistem madrasah sepertihalnya :

Pertama dari segi pendidik dan tenaga pendidik: Dengan pembentukan sistem kolaborasi Madrasah Diniyah Pondok Pesantren Nurul Jadid yaitu biro pendidikan dan kurikulum disamaratakan dengan santri putra maka disana terdapat "Club Working", Dengan adanya club working tersebut dalam bidang studi yang akan diajarkan dan yang akan di terapkan tehadap siswa dapat dibicarakan dan dimaksimalkan keaktifannya dengan baik dalam kelompok kerja. Termasuk pula dalam hal permasalahanpermasalahan yang terjadi dalam pembelajaran bisa diutarakan dalam forum, sehingga dapat tersolusikan dengan baik.

Dengan adanya forum tersebut bisa saling mengingatkan dan berbagi pengetahuan sesama antar pendidik dan tenaga kependidikan. Sehingga dengan perubahan sistem yang ada juga perlu diperkokoh kembali adanya pembentukan karakter yang baik, agar dapat di contoh dengan baik oleh peserta didik. Sepertihalnya target pencapaian kualitas guru yang meliputi kompetensi pedagogik, kompetensi kepribadian, 
kompetensi sosial dan kompetensi profesional guru dalam mengajar. juga target pencapaian tenaga kependidikan yang meliputi soft skill staf atau karyawan dalam bekerja dan kehadian karyawan di tempat kerja. Sehingga meraih out put terhadap peserta didik sepertihalnya disiplin dalam kelas, meningkatnya kehadiran siswa, menambah keaktifan siswa dalam kelas dan menambah kesopanan peserta didik. Dalam perubahan mindset yang baik inilah sangat diperlukan oleh sumber daya madrasah. Dengan adanya pertemuan khusus ini, diadakan knowledge sharing antar sesama guru, agar sesama guru sama-sama mengetahui tentang perkembangan muridnya di kelas.

Kedua dari segi kualitas siswanya : Untuk menambah kualitas pengetahuan santri dalam ketuntasan materi pembelajaran di madrasah diniyah dan agar bertambahnya materi yang dipelajari, kedisiplinan kehadiran siswa di kelas, keefektifan siswanya dan bertambahnya konsentrasi siswa dalam belajar, sehingga siswa lebih nyaman belajar dan lebih bertambah ilmunya dengan menuntaskan materi-materi yang telah diajarkan. Di madrasah juga diadakan buku pedoman pencapaian peserta didik dalam materi pembelajaran dan kehadiran juga lebih efektif dikarenakannya bantuan dari ibu asuh yang ada di pondok pesantren. Dengan adanya sistem yang ada di madrasah diniyah sudah cukup membantu belajar siswa untuk mencapai mata pelajaran agama, meskipun tidak semua pengetahuan dimiliki peserta didik namun dikarenakan guru yang baik, bagaimana cara menyampaikan ilmu atau materi maka hal tersebut bisa menjadi tauladan yang baik untuk di contoh oleh seorang murid. Dan metode yang dilakukan terhadap siswa ialah dengan metode diskusi, praktek, media visuai dan audio visual.

Jadi knowledge sharing yang digunakan ialah tacit knowledge pemimpin yang diberikan terhadap bawahannya, sehingga dengan hal itu pemimpin bisa menciptakan knowledge explicit yang didapat dari bawahan pula dan terjadi timbal balik pengetahuan.

\section{Melaksanakan Pelatihan}

Strategi kedua ialah melaksanakan kegiatan pelatihan. Dengan diadakannya sebuah pelatihan terhadap karyawan, peserta didik, dan pendidik akan menambah wawasan mereka terutama dalam mengembangkan bakat, wawasan, pengalaman dalam belajar dan mengabdi. Sebagai upaya memberi dampak baik dalam menambah pengalaman belajar mereka.

Untuk mening-katkan kualitas tenaga kerja di Madrasah, beberapa cara sudah dilakukan misalnya mengadakan kegiatan workshop dan pelatihan untuk sumber daya di madrasah. Dalam meningkatkan kesadaran guru tentang pentingnya mencintai serta melayani murid dengan baik biasanya sekolah mendatangkan penyaji atau guru dari luar pondok pesantren dan kadang pula dari keluarga pengasuh sendiri untuk melihat perkembangan guru dan karyawan di madrasah. Pelatihan yang diadakan dimadrasah merupakan salah satu cara dalam mendorong dan memotivasi siswa agar lebih giat dan fokus dalam belajar. Maka dari itu, dengan adanya motivasi tersebut sebagai penangkal siswa yang dapat mendorong kualitas belajar peserta didik di Madrasah Diniyah dan juga memotivasi peserta didik agar bangkit untuk menciptakan perubahan atau inovasi yang baru guna meningkatkan kualitas pendidikan. Tujuan utama diadakannya pelatihan ialah sebagai salah 
satu sistem yang memberikan kemajuan atau perkembangan yang baik dengan harapan bisa meningkatkan ketekunan dan semangat sumber daya madrasah dalam belajar, mengajar dan mengabdi

Pelatihan merupakan peranan penting untuk menentukan efektiftas dan efisiensi kinerja karyawan. Dengan adanya pelatihan dapat memberi banyak manfaat seperti halnya meningkatkan kerjasama antar karyawan guna mengembangkan pribadi karyawan, memenuhi kebutuhan perencanaan sumber daya manusia dan meningkatkan kuantitas karyawan. Dengan diadakannya pelatihan sangatlah mendidik para karyawan sehingga memberikan keunggulan bagi karyawan dalam berdaya saing antar lembaga pendidikan. (Mega Karinda dkk, 2016: 390). Pelatihan dapat diartikan sebagai upaya kegiatan yang dilaksanakan oleh individu atau kelompok untuk mempertajam ilmu yang sudah di lakukan oleh seseorang, kelompok, dan lembaga pendidikan, sehingga dengan adanya bekal ilmu tersebutlah dapat dijadikan tambahan ilmu yang sesuai dengan kepentingan pekerjaan yang sedang dilakukan (Angrian Pertama, 2013: 250).

Dengan diadakanya pelatihan atau pengembangan untuk karyawan yang bertujuan untuk meningkatkan kinerja karyawan sehingga dapat bekerja lebih baik, yang bisa meningkatkan kepuasan kinerja serta dapat meningkatkan kompensasinnya yang secara non financial ataupun financial (Angrian Pertama, 2013) Dengan adanya pelatihan yang telah diberikan bisa menumbuhkan pengetahuan yang dapat disalurkan.

\section{Pengawasan Kepala Madrasah}

Strategi yang ketiga ialah sistem pengawasan dari seorang pemimpin. Dengan adanya supervisor dalam sebuah lembaga tidak lain ialah dengan tujuan untuk mengetahui sejauhmana lembaga tersebut mengalami peningkatkan, sehingga sebagai seorang supervisor atau kepala madrasah bisa mengontrol dengan tujuan meningkatnya kualitas sumber daya manusia di lembaga pendidikan secara terus-menerus. Dengan diadakannya pengawasan terhadap kinerja pendidik dan karyawan di madrasah dari segi kedisiplinannya, pengajaran dan aktifitas sumber daya akan diketahui peningkatannya. Hal ini merupakan pendorong untuk tencapainya suatu tujuan lembaga.

Fungsi utama pengawasan ialah bertujuan untuk memastikan bahwa setiap karyawan yang memiliki tanggung jawab bisa bekerja dengan sebaik mungkin dan maksimal. Sehingga seorang pemimpin mengetahui kinerja bawahannya apabila ada kesalahan dan penyimpangan kinerja karyawan (Adi Ansari, 2016: 24) Sebagai seorang kepala madrasah, selain mengawasi karyawannya juga perlu mengontrol seluruh kegiatan guru di sekolah. Karena keberhasilan seorang guru sangatlah dipengaruhi dengan adanya pengawasan dari kepala madrasah. Maka dari itu seorang pemimpin dituntut untuk memiliki kemampuan yang terampil dalam berperan sebagai seorang supervisor (Yoserizal Bermawi dan Tati Fauziah, 2015:18-19). Sistem pengawasan bertujuan untuk mengontrol kegiatan sesuai dengan optimalisasai perencanaan agar sesuai dengan yang direncanakan. (Adi Ansari, 2016)

Dengan adanya pengawasan pemimpin secara langsung, hal ini dapat tecipta adanya explicit knowledge karena ternyadi 
komunikasih yang mudah untuk disampaikan dan didapat.

\section{Adanya Reward dan Punisment}

Strategi keempat ialah dengan diadakannya reward. Beberapa fungsi adanya reward ialah sebagai motivator karyawan, pendidik dan peserta didik untuk berkualitasnya sumber daya manusia di madrasah. Oleh karena itu, sepertihalnya riward yang diberikan terhadap sumber daya yang berupa apresiasi di Madrasah Diniyah Annafi'iyah Nurul Jadid ialah guru TU terbaik, guru karismatik, dan bintang pelajar dan punisment yang di berikan ialah berupa teguran pertama, kedua, ketiga dan pen DEOan. Dengan adanya apresiasi terhadap karyawan menambah kinerja karyawan itu tersendiri. Hal ini menjadi sebuah keunikan karena tidak semua lembaga bisa menghargai jasa seorang karyawan hanya sebatas hadiah saja.

Riward merupakan pemberian hadiah kepada tenaga pendidikan atau pendidik untuk memotivasi kinerja sumber daya untuk menjadi lebih baik kinerjanya (Bernhard Tewal dan Irvan Trang Kevin Tangkuman, 2015: 886). Karena riward sangatlah dibutuhkan untuk meningkatkan kualitas dan tanggung jawab kinerja karyawan (Silfia Febrianti, 2014: 4). Dengan diadakannya riward disuatu lembaga pendidikan tidak lain ialah untuk meningkatkan motivasi karyawan, guru ataupun siswa agar lebih giat lagi untuk bekerja dan belajar, sehingga dengan diberikannya hadiah atau penghargaan tersebut bisa membantu meningkatkan kualitas kinerja untuk lebih baik. Penghargaan ini dilakukan dengan harapan untuk merangsang prestasi kinerja (Neni Triana Siregar dan Suryalena, 2017: 2).
Dari hasil empat strategi tersebut dapat dihasilkan bahwa berhasilnya merubah madrasan untuk menjadi lebih baik dari pada sebelumnya ialah diperoleh melalui strategi knowledge sharing, sehingga dapat meningkatkan kualitas sumber daya yang ada di Madrash Diniyah Annafi'iyah Nurul Jadid menjadi lebih baik dari pada sebelumnya.

\section{KESIMPULAN}

Strategi knowledge sharing merupakan cara pemimpin untuk merubah kualitas sumber daya madrasah untuk menjadi lebih baik dan terus maju. Dengan pengetahuan dan pengalaman seorang pemimpin yang lebih banyak maka madrasah memiliki peluang untuk terus maju.

Strategi knowledge sharing yang telah terimplementasikan di madrasan memiliki tujuan 1. Untuk mendapat pengetahuan lebih dan berubah menjadi lebih baik; 2 . Memberikan informasi melalui atasan terhadap bawahan dan bawahan terhadap atasan. 3. Mendapat pengalaman lebih 4. tetap menjaga kualitas sumber daya manusia yang ada di madrasah. Dan karena strategi pemimpinlah yang menjadi titik pusat informasi tersebar terhadap bawahannya dan bisa dijadikan alat untuk terus maju untuk kedepannya.

\section{KEPUSTAKAANACUN}

A.Chairil, Muhammad Darwis, And Jamaluddin. 2016. "Pengaruh Fungsi Kepemimpinan Terhadap Motivasi Kerja Pegawai Padakantor Dinas Pendidikan Kabupaten Sinjai." Jurnal Office 2 (1): 2.

Aisyah, Merisa Fajar, Wiji Utami, Sunardi, And Sudarsih. 2017. "Kualitas Sumber Daya Manusia , Profesionalisme Kerja , Dan Komitmen Sebagai Faktor 
Pendukung Peningkatan Kinerja Karyawan Pdam Kabupaten Jember." Jurnal Ekonomi Bisnis Dan Akuntansi Iv (1): 132.

Almasri, M Nazar. 2016. "Manajemen Sumber Daya Manusia: Imlementasi Dalam Pendidikan Islam." Kutubkhanah: Jurnal Penelitian Sosial Keagamaan 19 (2): 137.

Ansari, Adi. 2016. "Manajemen Tenaga Pendidik Dan Kendidikan Perspektif Al- Qur'an." Jurnal Pengembangan Masyarakat Islam 9 (3): 24.

Aristanto, Deny Bagus. 2017. "Pengaruh Knowledge Sharing Terhadap Individual Innovation Capability Dan Kinerja Karyawan (Studi Pada Pt. Pln (Persero) Unit Induk Pembangunan Sulawesi Bagian Utara)." Jurnal Emba 5 (2): 1541.

Dwimadyasari, Vira, And Ade Irma Susanty. 2015. "Pengaruh Faktor Individu, Organisasi, Dan Teknologi Terhadap Knowledge Sharing (Studi Pada Pt Perusahaan Listrik Negara (Persero) Distribusi Jawa Barat Dan Banten)." E-Proceeding Of Management 2 (1): 25 26.

Febrianti, Silfia, Mochammad Al Musadieq, And Arik Prasetya. 2014. "Pengaruh Reward Dan Punishment Terhadap Motivasi Kerja Serta Dampaknya Terhadap Kinerja ( Studi Pada Karyawan Pt . Panin Bank Tbk . Area Mikro Jombang )." Jurnal Administrasi Bisnis (Jab) 12 (1): 4.

Hadi, Muhammad, Djailani Ar, And Sakdiah Ibrahim. 2014. "Strategi Kepala Madrasah Dalam Meningkatkan Mutu Pendidikan Pada Min Buengcala Kecamatan Kuta Baro Kab Aceh Besar." Jurnal Administrasi Pendidikan 4 (2): 42-43.

Hanggara, Agustinus Hari, Imanuel Sairo Awang, And Bejo. 2016. "Pengaruh
Model Pembelajaran Numbered Heads Together Terhadap Hasil Belajar." Jurnal Pendidikan Dasar Perkhasa 2 (1): 80.

Karinda, Mega, Jantje L Sepang, And Christoffel M O Mintardjo. 2016. "Kajian Terhadap Pelatihan Dan Pengembangan Karyawan Dalam Upaya Peningkatan Kinerja Pelayanan Bank Sulutgo Cabang Manado." Jurnal Berkala Ilmiah Efisiensi 16 (3): 390.

Kristiawan, Muhammad. 2015. "Telaah Revolusi Mental Dan Pendidikan Karakter Dalam Pembentukkan Sumber Daya Manusia Indonesia Yang Pandai Dan Berakhlak Mulia." Jurnal Ta'dib 18 (1): 21.

Maulana, Fajar, R Andi Sularso, And Purnamie Titisari. 2018. "Analisis Pengaruh Knowledge Sharing Dalam Penerapan Sistem Manajemen Mutu Iso 9001:2008 Terhadap Kinerja Inovasi Dan Kinerja Karyawan." Jurnal Manajemen \& Kewirausahaan 6 (1): 59.

Novian Setyaji Saputro Dan Yuniadi Mayowan. 2018. "Pengaruh Knowledge Sharing Terhadap Individual Innovation Capability Dan Kinerja Karyawan (Studi Pada Karyawan Rumah Opa Kitchen And Lounge)." Jurnal Administrasi Bisnis (Jab) 55 (3): 9.

Ofori, Daniel, Abraham Osei, Shadrach Ato Mensah, And Ernest Kwame Affum. 2015. "Innovation And Knowledge Sharing: A New Competitive Advantage In The Mobile Telecommunication Industry In Ghana." Science Journal Of Business And Management 3 (5): 158. Https://Doi.Org/10.11648/J.Sjbm.2 0150305.14.

Pertama, Angrian. 2013. “Analisis Pengaruh Pelatihan, Pengembangan, Dan Kompensasi Terhadap Kinerja 
Karyawan Bank Mega Kcp Serang." Jurnal Mix Iii (2): 250.

Raharjo, Husaini Usman Dan Nuryadin Eko. 2013. "Strategi Kepemimpinan Pembelajaran Menyongsong Implementasi Kurikulum 2013.” Cakrawala Pendidikan, No. 1: 2.

Rakhmah, Syifa Nur. 2017. "Strategi Knowledge Management Untuk Meningkatkan Pengetahuan Berdasarkan Knowledge-Based Organizational Model." Information System Educator And Professionals 1 (2): 116.

Redaksi, Tim. 2008. "Tesaurus Bahasa Indonesia Pusat Bahasa," 435.

Rumaisha, Mayang Nur Fauziyah, Ninis Agustini Damayani, And Asep Saeful Rohman. 2014. "Perilaku Knowledge Sharing Multi Bahasa Pada Komunitas." Jurnal Kajian Informasi Dan Perpustakaan 2 (2): 90.

Shadily, John M. Echols Dan Hassan. 2010. Kamus Inggris Indonesia.

Siregar, Neni Triana, And Suryalena. 2017. "Pengaruh Penilaian Kinerja Karyawan Dan Reward Terhadap Prestasi Kerja Karyawan Pada Hotel Sapadia Pasir Pengaraian." Jom Fisip 4 (2): 2.

Siswanto. 2014. "Madrasah Unggulan Berbasis Pesantren." Ulumuna Jurnal Studi Keislaman 18 (1): 170-72.

Suprapto, Cahyo Adi, And Setiawan Assegaff. 2017. "Analisis Dan Perancangan Knowledge Management System Pada Sma Negeri 6 Kota Jambi." Jurnal Manajemen Sistem
Informasi 2 (3): 532.

Syukron, Buyung. 2016. "Paradigma Implementasi Konsep Revolusi Mental (Studi Analisis Dalama Perspektif Lembaga Pendidikan Islam)." Jurnal Elementary 2 (3): 30.

Tangkuman, Kevin, Bernhard Tewal, And Irvan Trang. 2015. "Penilaian Kinerja, Reward, Dan Punishment Terhadap Kinerja Karyawan Pada Pt. Pertamina (Persero) Cabang Pemasaran Suluttenggo." Jurnal Emba 3 (2): 886.

Vrizka, Viranda, And Anita Silvianita. 2016. "Pengaruh Knowledge Sharing Terhadap Kinerja Organisasi Pada Badan Lingkungan Hidup Provinsi Sumatera Utara." E-Proceeding Of Manajement 3 (2): 1849.

Wandrial, Son. 2011. "Strategic Management Dan Strategic Leadership: Dua Sisi Mata Uang Kemampuan Untuk Hadapi Tantangan Perubahan Lingkungan Yang Drastis." Binus Bussiness Review 2 (1): 422.

Widodo. 2013. "Peran Knowledge Sharing Terhadap Kinerja Ukm Berbasis Sikap Kewirausahaan.” Ekobib 14 (2): 19-20.

Wijayanti, Desi Putri, And Didi Sundiman. 2017. "Pengaruh Knowledge Management Terhadap Kinerja Karyawan (Studi Empiris Pada Pt. Sms Kabupaten Kotawaringin Timur)." Derema Jurnal Manajemen 12 (1): 71.

Yoserizal Bermawi Dan Tati Fauziah. 2015. "Supervisi Kepala Sekolah Terhadap Kompetensi Profesional Guru." Jurnal Pesona Dasar 1 (4): 18-19. 